\title{
A Conceptual Model of Admission System and Performance Evaluation for a University
}

\author{
Amardeep Kaur \\ Punjabi University Regional Centre for IT \& Mgmt \\ Mohali, India
}

\author{
Sucharu Hasija \\ Punjabi University Regional Centre for IT \& Mgmt \\ Mohali, India
}

\begin{abstract}
University admission process is a key process in a university. It affects the overall resources of the universities and its quality constraints. There are multiple constraints on which the decision to start or upgrade a typical course admission depends rather than only student to teacher ratio. There is need of effective data mining to find dependent constraints and trend, as it is suited as one of the best for analysis in education system. So firstly, a dimensional model of the university admission system is designed and then it is checked, whether the model validates the requirements or not. The study presented a way to find the trend in the education system for the courses with assessing admission capacity alongside with management and evaluation of different affecting factors on the student's performance.
\end{abstract}

\section{Keywords}

Dimensional model, Higher education, Admission management system, Performance Evaluation

\section{INTRODUCTION}

In present times, running a university is akin to operating all the businesses needed to support a small village [10]. It is difficult to analyze the working conditions and performance of students to take right decisions. Also, Determining exact admission capacity for a particular course is a very complex process as it affects the overall functionality and resources management. But, the current focus is to maximize the student's intake by evaluating what students are buying in the term of courses and normally decisions regarding admission capacity are merely based on the student to teacher ratio [3]. So, There is a need to have a more systematic approach. Nowadays, it is possible to analyze each and every factor that affects. Student, department, program are important steps in analyzing and discovering strengths and weaknesses of students [7] and to exemplify the excellence, greater emphasis should be on meeting students' needs and expectations, implementing the change by enhancing quality of service provided to students, enrolment, tutorial allocations, etc. [17]. But the consequence of any change will be perceived in several educational terms. In India, decision-making is still very challenging. Religion, caste, community and other factors play a major role in admissions. Admission seats of any course are based on different reservation policies, which makes impossible for the university to analyze them [16].

Every university uses a database to store its fundamental data and information useful for conducting only day-to-day transactions. Data sitting in these databases are of little use unless they are processed, converted and expressed in intelligent ways to present decision-makers with valued information [7] using qualitative techniques that necessitate the use of data warehousing and mining techniques.

\begin{abstract}
A data warehouse mapping is done using Dimensional model to analyze attributes in different scenarios. Dimensional modeling is a logical design technique for the data warehouse that seeks to present the data in a standard framework that is intuitive and allows for high-performance access [3].
\end{abstract}

In India, Different universities can have different criteria for the altering the admission capacity. So, to limit the scope of it, the present study is intended to design a dimensional model for Punjabi university. Punjabi University was established on the 30th April 1962 under the Punjabi University Act 1961. Initially, the University was started with the objective of developing and promoting the language, literature and culture of the Punjabi people. Presently it has fifty-five teaching and research departments with admission capacity nearly of 9000 students and provides international standard facilities for students and researchers in various disciplines.

The study proposes a conceptual framework to develop tools so that could be utilized to evaluate quality, perform analyses and diagnoses, evaluate dependability to the standards and practices of curricula and syllabi, trend and provide the required decision support especially by building data warehouse while planning for taking decisions regarding enrollment of students and further steps for building data warehouse [11].

\section{RELATED WORK}

Decision issues in the present world have become more sophisticated, time consuming, difficult for decision makers and become complex and more complex for a large university. A lot of research efforts have been made to find the key affecting and dependent factors for the university admission process and also the study on the evaluation process of the university is done that comprises the first requirement phase of the model. The most of work so far is done on managing academic resources, Admission management system, Quality factors, and Conceptual model validation. Where, [17] represents the decision support systems and data mining are best suited for the decisions in the higher education. In $[8,12]$ represents the importance of the data mining and advantages for using it in the higher education. So there is a need to have a more systematic decision-making support.

Different Decision support system were offered in the academic domain to achieve different functionalities, to determine admission capacity and resource management $[1,2]$ used a supply chain mechanism, [5] used Artificial intelligence, [4] uses a mathematical model and [16] used artificial neural network based on Indian Education system, to evaluate student performance [17] used a decision tree model and [7,15] uses statistics on student marks.

In [14], uses different tools of TQM to apply on the higher 
education for considering the quality issue in the higher education. In [6] presents the various factors that effect student's choice for the college before taking admission in the college by the students. This paper helps to identify the various important factors to be considered and the involvement of the students in the admission process to extract the important attributes to consider for quality.

\section{A FRAMEWORK OF UNIVERISTY ADMISSION SYSTEM 3.1 Conceptual Schema Design}

To enhance the analytical capabilities in the current scenario, there is a need to analyze every factor that came between a complex relationship between the student and the university. As it is shown in Figure 1, the university has many faculties based on the different specializations, further faculties has many departments, and on the other side, numerous students apply to different course specializations (as computer science branch for master of technology course) of the courses to the university in a particular department, at end university deal its students by teaching a subject by its staff in a Facility for the specific academic term. This relationship is the base for the dimensional model.

The literature study shows the important factors and attributes to deal with and which are to be required to analyze and to include them in design, also a study of the academic structure and evaluation process of Punjabi university help us to that. Once the important factors are extracted it followed the dimensional model life cycle for drafting the Dimensional model. The main evaluation of the model is on the two important facts that are student marks and its regularity (attendance) towards the university. Both of them are based on four main dimensions, first is the subject which can be further analyzed on its complexity, type of study and examination system, second on the staff member, teaching that very subject, which can be further analyzed by its experience, specialization and its position in the department, third one is the Facility provided to students, and last on the student itself, which can be further analyzed, on its previous performance and academic Achievements.

Going through the life cycle, the proposed model is expanded to snowflake by extracting out the information of the students to the applicant table to enhance the model's capability by storing the information of even the non-selected students with the selected one's in the Applicant Table as shown in figure 2.

\subsection{Capabilities of Dimensional Model}

The proposed model has three main functionalities. First, it is able slice and dice the all applicant data, whether or not he/she was gone selected in the university for that specific course to find the trend and affecting factors in the admission of students. Secondly it analyze the performance of the student on the basis of its marks and its regularity to the subject, to faculty and to facility, to find out the various reasons and factors for its performance to make decisions for the next academic term. Last functionalities is to analyze the students perspective for the university by adding two attributes to get the more refined knowledge about university, quality and Student satisfaction, are filled by students while filling the form to take admission in the university.

1. Why are you selecting Punjabi university?

2. What do you expect from the university to do for you?

To the fulfillment of this, the various factors can be considered from [6] and placed in a list with numbers and stored the details with Applicant data. On the basis of the model, the data warehouse can be built on it by following the steps in the next subsection.

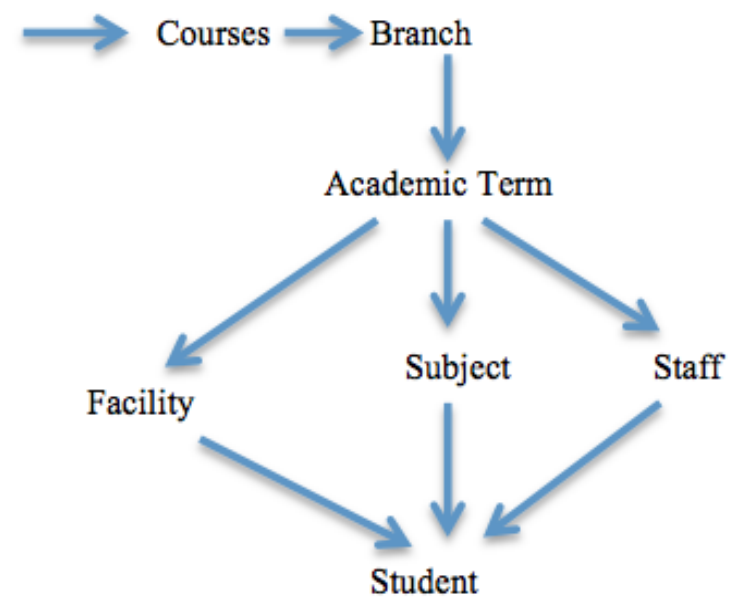

Figure 1. Basic Relationship of University with Student 


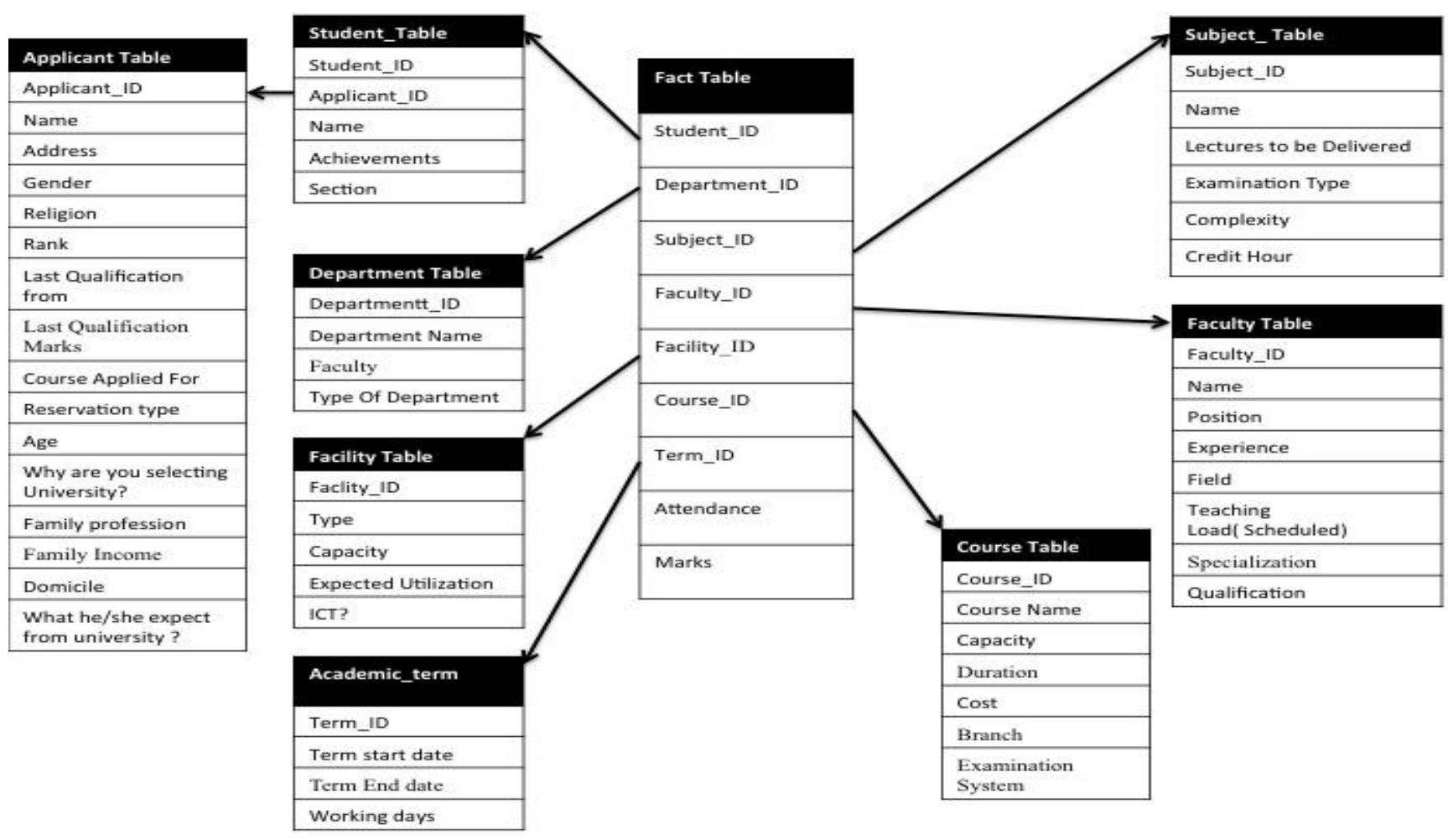

Figure 2 Dimensional model of University Admission System

\subsection{Steps for building data Warehouse}

Once the design work is done, the data warehouse can be built on that Architecture design using Figure 3 as shown below:

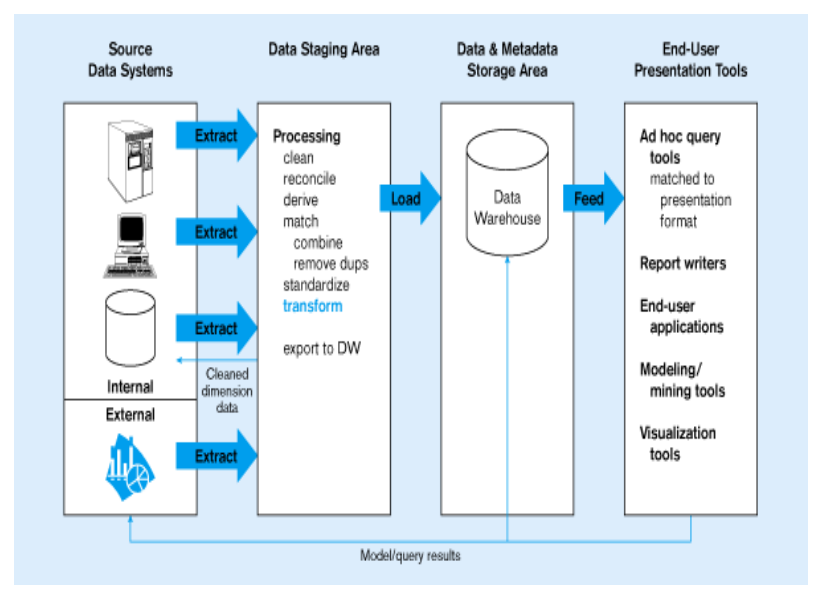

Figure 3. Architecture for building Data warehouse [11]

In this data is first extracted from operational data stores and then stored temporary into a buffer area. Then data is preprocessed includes cleansing, scrubbing fixing data entry errors, deletion of unwanted columns and transforming data into a more normalized standard. Then transformed data are loaded and indexed into the data warehouse.

All the processing to loading the data in the data warehouse, from the operation data store is called ETL, Where ETL stands for Extraction, Transform, and Load. In Extraction, the data is loaded in the staging area, cleaned and reject unwanted data. Then transform that data to the structure of the dimensional model of the data warehouse.

\section{RESULTS AND VALIDATION}

The Multidimensional Models are the blueprint of the data warehouse, so the correctness and quality of the model play very important role. It is important to validate the model first to prevent the errors and quality issues to pass on to the next phases for building a data warehouse. For this, a small conceptual database of the data warehouse is made and applying various queries tests model, to check whether the requirements like, What the Applicants while filling the Admission form expect from the university helps to provide the attribute which is most important for the university to handle, What are the least scoring subject per course helps to trigger out the reasons behind this and study will help to provide the trending courses and for which courses most of the Applicants are applying are achievable or not.

The various queries are applied on them and their result is shown as in Table 1. 
Table 1 Requested queries and result

\begin{tabular}{|c|c|c|}
\hline Questions or Requirements for the data warehouse & Answers & $\begin{array}{l}\text { Requirement } \\
\text { s Meets? }\end{array}$ \\
\hline $\begin{array}{l}\text { What is the average percentage of marks of students who got any achievements in campus } \\
\text { for the specific branch? }\end{array}$ & $77.05 \%$ & YES \\
\hline $\begin{array}{l}\text { How many students have last qualification from Punjabi university? What is the average } \\
\text { percentage of marks of them? }\end{array}$ & $75.35 \%$ & YES \\
\hline What are average marks of students who taught by the most utilized staff? & $76.19 \%$ & YES \\
\hline $\begin{array}{l}\text { Which are the } 2 \text { subjects with the lowest attendance according to average marks of } \\
\text { students per department per academic term? }\end{array}$ & $62.2 \%$ & YES \\
\hline $\begin{array}{l}\text { Which are the } 2 \text { subjects with highest pass percentage according to average marks of } \\
\text { students per department per academic term? }\end{array}$ & $\begin{array}{l}\text { CS-714, } \\
\text { CS-712 } \\
\text { (Subject - } \\
\text { ID) }\end{array}$ & YES \\
\hline What is the teacher to student ratio per course? & 4.2 & YES \\
\hline $\begin{array}{l}\text { What is the most important attribute expected by the students while admission per course } \\
\text { per department? }\end{array}$ & $\begin{array}{l}\text { 25(Regular } \\
\text { Classes) }\end{array}$ & YES \\
\hline $\begin{array}{l}\text { Do the Model will able to provide the ratio of a number of applicants to the number of } \\
\text { seats for that courses per region or per year? }\end{array}$ & NA & YES \\
\hline $\begin{array}{l}\text { Do the Model be able to list all the subjects with descending order of their Complexity and } \\
\text { the average pass percentage of that subject? }\end{array}$ & NA & YES \\
\hline $\begin{array}{l}\text { Do the Model able to analyze the effect of any change in faculty or facility in-between of } \\
\text { the academic term? }\end{array}$ & NA & NO \\
\hline $\begin{array}{l}\text { Do the Model able to list all the facilities with their expected utilization and current } \\
\text { utilization per department per term? }\end{array}$ & NA & YES \\
\hline Do the Model able to analyze the role of department Multi department courses? & NA & NO \\
\hline
\end{tabular}

In the table, in first column comprises of important queries, Which are used for the analysis of the university admission system, then the answer to that queries and last it is checked that it fulfills the requirements or not. It is evaluated that the dimensional model capability is $83.34 \%$ to the requirements.

\section{CONCLUSION}

The study helps to provide the detailed analysis of the different factors, which affects the admission of students and provide help to find the trend in the education system. This study can be extended to implementation of Data warehouse, more detailed data to students during study to analyze its performance and the find the satisfaction ratio, to find what students, subjects, and teachers are expecting from a university to ensure it's quality and how these can be fulfilled.

\section{REFERENCES}

[1] S. Vinnik, S. Vinnik, M. H. Scholl, and M. H. Scholl, "UNICAP: Efficient Decision Support for Academic Resource and Capacity Management," \{E-Government\} Towar. Electron. Democr., vol. 3416, pp. 235-246, 2005.

[2] S. Mansmann and M. H. Scholl, "Decision support system for managing educational capacity utilization," IEEE Trans. Educ., vol. 50, no. 2, pp. 143-150, 2007.

[3] S. F. M. Dahlan and N. a. Yahaya, "A System Dynamics Model for Determining Educational Capacity of Higher Education Institutions," 2010 Second Int. Conf. Comput. Intell. Model. Simul., pp. 285-290, 2010.
[4] F. Aduol, "A model for estimating student unit cost and staffing requirements for university academic programs with reference to Kenyan public universities," High. Educ. Policy, vol. 14, no. 2, pp. 117-140, 2001.

[5] R. Vohra and N. Narayan Das, "Intelligent Decision Support Systems For Admission Management In Higher Education Institutes," Int. J. Artif. Intell. Appl., vol. 2, no. 4, pp. 63-70, 2011.

[6] D. Pushkar, S. S. Kumar, and N. Surenthiran, "Factors affecting choice of Engineering Colleges in Odisha , India," Res. J. Manag. Sci., vol. 2, no. 4, pp. 14-20, 2013.

[7] D. Deniz and I. Ersan, "An Academic Decision Support System Based on Academic Performance Evaluation for Student and Program Assessment," Int. J. Eng. Educ., vol. 18, no. 2, pp. 236-244, 2002.

[8] N. Trivedi, "Data Mining Functions in Advanced Education," Int. Conf. Adv. Comput. Appl., pp. 36-39, 2013.

[9] D. M. Farrell, "Dimensional Modeling: In a Business Intelligence Environment.", IBM redbook publication, pp. 670, 2006

[10] Kimball, Ralph; Reeves, Laura; Ross, Margy; and Thornthwaite, Warren. The Data Warehouse Lifecycle Toolkit. New York: John Wiley \& Sons, Inc., 1998.

[11] Y. Bassil, "A Data Warehouse Design for A Typical University Information System," J. Comput. Sci. Res., vol. 1, pp. 12-17, 2012. 
[12] B. Baradwaj and S. Pal, "Mining educational data to analyze student's performance," Int. J. od Advamced Comput. Sci. Appl., vol. 2, no. 6, pp. 63-69, 2012.

[13] V. P. Bresfelean, N. Ghisoiu, R. Lacurezeanu, and D. A Sitar-Taut, "Towards the development of decision support in academic environments," Proc. Int. Conf. Inf. Technol. Interfaces, ITI, pp. 343-348, 2009.

[14] H. M. Jani, "Intellectual Capacity Building in Higher Education: Quality Assurance and Management," Int. Conf. New Trends, vol. 5, pp. 361-366, 2011.
[15] M. Tanna, "Decision Support System for Admission in Engineering Colleges based on Entrance Exam Marks," vol. 52, no. 11 , pp. 38-41, 2012

[16] C. Science, S. Chandrasekharendra, and S. Viswa, "An Automated Implementation of Indian University Admission," ICTACT J. SOFT Comput., vol. 6956, no. April, pp. 767-771, 2014.

[17] Long P, Tricker T, Rangecroft M, and Gilroy P "Measuring the Satisfaction Gap: Education In the Market place", vol.10, pp. 772-778,1999 